Article

\title{
The Effects of Carbon Content on the Anisotropic Deformation Mechanism of Boron Carbide
}

\author{
Jun $\mathrm{Li}^{1}$, Lisheng Liu ${ }^{2,3}$, Shuang $\mathrm{Xu}{ }^{1, *}$, Jinyong Zhang ${ }^{2}$ and Yuanli $\mathrm{Wu}^{1}$ \\ 1 Hubei Key Laboratory of Theory and Application of Advanced Materials Mechanics, School of Science, \\ Wuhan University of Technology, Wuhan 430070, China; whut_lijun@126.com (J.L.); \\ m15871438618@163.com (Y.W.) \\ 2 State Key Laboratory of Advanced Technology for Materials Synthesis and Processing, Wuhan University of \\ Technology, Wuhan 430070, China; liulish@whut.edu.cn (L.L.); jyzhang@whut.edu.cn (J.Z.) \\ 3 Institute of Advanced Material Manufacturing Equipment and Technology, \\ Wuhan University of Technology, Wuhan 430070, China \\ * Correspondence: xu_shuang@whut.edu.cn; Tel.: +86-027-8765-1820
}

Received: 4 September 2018; Accepted: 25 September 2018; Published: 29 September 2018

check for updates

\begin{abstract}
The effects of carbon content on the mechanical properties and deformation mechanisms of boron carbides were investigated by first-principles calculations, based on the density functional theory. The $\mathrm{B}_{12}-\mathrm{CBC}(13.33$ at $\% \mathrm{C})$ and $\mathrm{B}_{10} \mathrm{C}_{2}^{\mathrm{P}}-\mathrm{CC}(28.75$ at $\% \mathrm{C})$ were studied and then compared with the deformation of regular $B_{11} C^{P}-C B C(20.0$ at \% $C)$. The results show the $B_{10} C_{2}^{P}-C C$, which has the lowest carbon content, has the highest strength and hardness as well as the lowest toughness. With the increase of carbon content, the rhombohedral symmetry will be broken and the three-atoms chains will be replaced by diatomic carbon chains. These changes may have an influence on their anisotropic deformation mechanisms. For the $\mathrm{B}_{12}-\mathrm{CBC}$, the destruction of icosahedra without bending three-atom chains causes structural failure for compression along the $c$ axis; while for compression along the $a$ axis, new B-B bonds are formed, causing an unrecoverable deformation; then it is gradually destroyed until full destruction. For the $\mathrm{B}_{10} \mathrm{C}_{2}^{\mathrm{P}}-\mathrm{CC}$, the anisotropic deformation mechanism is not obvious. For both loading directions, the breakage of $\mathrm{B}-\mathrm{C}^{\mathrm{P}}$ bonds causes the stress to drop, suggesting that the structure is beginning to be destroyed. Finally, the icosahedra are fully destroyed, resulting in structural failure.
\end{abstract}

Keywords: boron carbide; first-principles method; carbon content; anisotropic deformation mechanism

\section{Introduction}

Boron carbide is characterized by many outstanding properties, such as thermal stability, extreme abrasion resistance, high hardness, and low density, which make it a promising material for a wide range of engineering applications, such as in semiconductors, refractory processes, abrasive power, and body armors [1-6]. The crystal structure of boron carbide is very complicated [7-9], it consists of 12-atom icosahedra located at vertices of a rhombohedral unit cell and the 3-atom chains lying along the main diagonal axis. This structure of boron carbide can also be described in terms of a hexagonal lattice, in which case the [0001] axis of the hexagonal lattice is related to the body diagonal of the primitive rhombohedral unit cell. There are two types of crystallographic sites, "polar" and "equatorial", within an icosahedron. Atoms at polar sites link the icosahedra together, while atoms at equatorial sites connect to chains. In addition, boron carbide is generally regarded to have R $\overline{3} \mathrm{~m}$ symmetry. However, this can be only true for a subset of the available atomic arrangements, since the substitution of carbon atoms into icosahedra may cause a distortion of the rhombohedral lattice, thereby reducing the crystalline symmetry [8]. 
Similar to other ceramic materials, the mechanical properties and deformation mechanisms of boron carbide strongly depend on its chemical compositions, microstructure, and fabrication processes [1,2,10-15]. In particular, depending on the synthesis conditions, boron carbide has a relatively broad composition range, from 8 to 20 at $\%$, with varying distributions of carbon (C) and boron (B) atoms into icosahedra and chains to form thermodynamically stable solid solutions, resulting in a complex phase diagram $[2,16]$. However, due to the complex structure of boron carbide, as well as the similarities of atomic form factors for X-ray diffraction [17] and nuclear scattering cross-sections $\left({ }^{11} \mathrm{~B}\right.$ and $\left.{ }^{12} \mathrm{C}\right)$ for neutron diffraction [9] between $\mathrm{C}$ and $\mathrm{B}$ atoms, it is a challenge to distinguish $\mathrm{C}$ from $\mathrm{B}$ atoms and identify their exact atomic positions at any specific carbon content experimentally. Several first-principle calculations have predicted two stable forms at 13.33 and 20 at $\% \mathrm{C}$, corresponding to $\mathrm{B}_{13} \mathrm{C}_{2}$ and $\mathrm{B}_{12} \mathrm{C}_{3}$ stoichiometries, respectively, represented by $\mathrm{B}_{12}-\mathrm{CBC}$ and $\mathrm{B}_{11} \mathrm{C}^{\mathrm{P}}-\mathrm{CBC}$, where superscript $p$ represents the polar site $[8,14,18]$. Since the maximum at $\% \mathrm{C}$ of boron carbide is still an unsolved question and debatable among the research [1,2,12,19], Ektarawong et al. [11] investigated the thermodynamic stability of carbon-rich boron carbide at different compositions, ranging from 20 to 33.33 at $\%$, using first-principles calculations. They concluded that apart from $\mathrm{B}_{4} \mathrm{C}$, the only carbon-rich boron carbide with 28.75 at \% $\mathrm{C}$, denoted by $\mathrm{B}_{2.5} \mathrm{C}$, is thermodynamically stable under high pressures with respect to $\mathrm{B}_{4} \mathrm{C}$ as well as pure $\mathrm{B}$ and $\mathrm{C}$ phases. The atomic configuration of the $\mathrm{B}_{2.5} \mathrm{C}$ is represented by $B_{10} C_{2}^{P}-C C$, where icosahedra $C^{P}$ atoms occupying the polar sites of the icosahedra without forming $C^{\mathrm{P}}-\mathrm{C}^{\mathrm{P}}$ bonds and $\mathrm{C}-\mathrm{C}$ denotes a diatomic carbon chain. They also suggested a possible route for experimental synthesis of $\mathrm{B}_{2.5} \mathrm{C}$ as well as a fingerprint for its characterization from the simulations of $\mathrm{x}$-ray powder diffraction.

The lattice constants, atomic bonding, mechanical properties, and deformation behaviors of boron carbide have been suggested to change with the carbon content $[1,2,15,20,21]$. Aselage et al. [20] determined the lattice constants of boron carbide by power x-ray diffraction for samples with compositions between $\sim 7.7$ and 20.5 at $\%$ C, and established the relationship between lattice constants and carbon contents. They concluded that the $a$ parameter increases almost linearly with the decrease of carbon content. The expended lattice constants maybe result from the difference in atom radii between $C$ and $B$ atoms. Further, neutron powder diffraction data [9] have shown that the chain bond length of boron carbide at about 13 at $\% \mathrm{C}$ is reduced $2-3 \%$ compared to that in boron- and carbon-rich materials. In addition, mechanical properties of boron carbide have been shown to change with the carbon content $[1,2,15,21]$. Nanoindentation measurements [21] have demonstrated that the hardness and elastic modulus of boron-rich boron carbides decrease with the increase of boron content, except for $B_{10.2} C$. Domnich et al. [2] and Taylor et al. [15] compared the elastic properties of boron carbide with different carbon contents. They concluded that the toughness of boron carbide decreases as the increase of boron content. In addition, the deformation mechanisms of boron carbide with different carbon contents is not the same [16-19]. An et al. [22-24] studied the deformation mechanism of boron carbides with different carbon contents under shear deformation, corresponding to $\mathrm{B}_{12} \mathrm{C}_{3}\left(\mathrm{~B}_{4} \mathrm{C}\right)$ and $\mathrm{B}_{13} \mathrm{C}_{2}$ and $\mathrm{B}_{14} \mathrm{C}$ stoichiometries. The deformation mechanism of $\mathrm{B}_{4} \mathrm{C}$ involves two steps. They found $\mathrm{a}$ unique 'plastic' deformation before failure, in which the $\mathrm{B}-\mathrm{C}$ bond between neighboring icosahedra breaks to form a reactive carbene, and the 3-atom chains have bent sufficiently for the carbene to form new bonds with $B$ atoms in the chain center. Then, the icosahedra begins to be destroyed, and finally structural failure occurs [22]. For $B_{13} C$, the structure deforms continuously without bending the 3-atom chain and then the structure fails suddenly [23]. For $B_{14} C\left(B_{12}-C B B\right)$, which is a boron-very-rich boron carbide, the brittle failure arises from the interaction between $\mathrm{B}_{12}$ icosahedra and the bent $\mathrm{C}-\mathrm{B}-\mathrm{B}$ chains [24]. Taylor et al. [15] also studied the effect of stoichiometry on the deformation behaviors of boron carbide under loading. They suggested that within all structures, the structural failure of boron carbides results from a sudden bending of the 3-atom chains under $c$ axis (the direction of 3-atom chains) compression. However, in our previous studies [25], we found that under $c$ axis compression, the deformation mechanism of $\mathrm{B}_{4} \mathrm{C}$ is the formation of new $\mathrm{B}-\mathrm{B}$ bonds between icosahedra and chains and not the chain bending. Thus, the deformation mechanism of boron carbide with different carbon 
contents proposed by Taylor et al. [15] may not be reasonable. Furthermore, since boron carbide has strong anisotropic elasticity, interatomic bonding, and deformation behaviors [25-27], it is necessary to investigate the anisotropic deformation mechanism for boron carbide and then further investigate the effects of carbon content on the deformation behaviors of boron carbides.

Although there are extensive experimental and theoretical studies about boron carbides, the anisotropic deformation mechanisms for boron carbide with different carbon contents, particularly those under uniaxial compressions, remain a mystery. Furthermore, since boron carbide powder are most likely a mixture of boron carbide configurations, to fully explain the failure process of boron carbide materials, it is necessary to understand the anisotropic deformation mechanism of boron carbide with different carbon contents. However, this has not been well understood. Understanding the anisotropic deformation mechanism for boron carbide with different carbon contents can also help us to identify 'soft' configurations that may initiate failure in boron carbide structures under impact loading.

In this article, two stable forms with 13.33 and 28.75 at \% $\mathrm{C}$, corresponding to $\mathrm{B}_{6.5} \mathrm{C}$ and $\mathrm{B}_{2.5} \mathrm{C}$ stoichiometries, respectively, by $\mathrm{B}_{12}-\mathrm{CBC}$ and $\mathrm{B}_{10} \mathrm{C}_{2}^{\mathrm{P}}-\mathrm{CC}$ were taken as examples for boron-rich boron carbide and carbon-rich boron carbide, respectively. Then the two stable configurations were used to investigate the mechanical behaviors and deformation processes of boron carbide by first-principles methods, based on density functional theory. The deformation mechanisms were compared with that of regular stable boron carbide $\mathrm{B}_{4} \mathrm{C}\left(\mathrm{B}_{11} \mathrm{C}^{\mathrm{P}}-\mathrm{CBC}\right)$ to understand the influence of carbon content. For each stable configuration, elastic properties as well as stress-strain responses under hydrostatic and uniaxial compressions were studied. To examine the anisotropic deformation mechanism, it is essential to investigate the deformation behaviors of boron carbide with different carbon contents under $c$ axis and $a$ axis compressions. The rest of this paper is organized in four sections. In Section 2, details about the computational methods are given. In Sections 3 and 4, we present the results and discussion about the mechanical properties and anisotropic deformation mechanisms of boron carbides with different carbon content. Some main conclusions are suggested in Section 5.

\section{Methods}

The density functional theory (DFT) has been considered to be one of the most accurate methods for the computation of physical properties and deformation mechanisms of solids [28-30]. The DFT and the plane-wave projector augmented wave (PAW) method with the local density approximation (LDA) functional, as implemented in the Vienna ab initio Simulation Package (VASP) periodic code [31-33], were used for all periodic calculations. To ensure accuracy and efficiency, tests were made before calculations to determine the number of k-points and the cutoff energy required. According to the test results, the plane-wave energy cutoff and the Monkhorst-Pack k-point mesh was set to be $800 \mathrm{eV}$ and $5 \times 5 \times 5$, respectively. The convergence criteria were set to be $1 \times 10^{-6} \mathrm{eV}$ energy difference for solving the electronic wave function and $1 \times 10^{-3} \mathrm{eV} / \AA$ force for geometry optimization. And the symmetry of the crystal structure was maintained during the calculations. These parameters could provide excellent convergence on the energy, force, stress, and structural parameters of boron carbides.

During the geometry optimization, all internal atomic coordinates, volume, and cell shape were fully relaxed and then the optimized models were obtained. To evaluate the mechanical properties of the two configurations, elastic constants (Cij), bulk modulus (B), shear modulus (G), Young's modulus (E), passion ratio $(v)$, Pugh's ductility index $(B / G)$, Vickers hardness $\left(\mathrm{H}_{V}\right)$, and anisotropy indexes $\left(\mathrm{A}^{\mathrm{U}}\right)$ were examined. The elastic constants $\mathrm{Cij}$ are related to the second derivative of the total energy with respect to strain, and they were derived from the stress-strain response as a function of various cell distortions from equilibrium configuration. The elastic stability of boron carbide was examined 
using Born stability criteria [11,15], as shown in Equation (1). Then, the other mechanical properties could be evaluated [34-36].

$$
\begin{gathered}
\mathrm{C} 11-|\mathrm{C} 12|>0, \\
(\mathrm{C} 11+\mathrm{C} 12) \times \mathrm{C} 33-2 \times(\mathrm{C} 13) \times 2>0, \\
(\mathrm{C} 11-\mathrm{C} 12) \times \mathrm{C} 44-2 \times(\mathrm{C} 14) \times 2>0, \\
\mathrm{C} 44>0
\end{gathered}
$$

To investigate the anisotropic deformation mechanism for boron carbide, we applied the uniaxial compressive strains along the $a$ axis and $c$ axis, while allowing full structure relaxation of the other five strain components. Then, the residual stresses after relaxation were less than $0.1 \mathrm{GPa}$. Thus, under the uniaxial compression, the other two axes were expanded during the relaxation. At each deformation step, a small increment (a 1\% compressive strain) was applied sequentially to the structure relaxed in the previous step. To perform the hydrostatic compression, hydrostatic pressure was also imposed on these models with a $20 \mathrm{GPa}$ increment, and then the total energy and volume strain were evaluated. Since the compressive strain was constrained in the deformation, the stress of the system could become negative after the structure changes or fails.

\section{Results}

\subsection{Structural and Elastic Properties}

In the present work, two optimized models with hexagonal lattice for $\mathrm{B}_{6.5} \mathrm{C}$ and $\mathrm{B}_{2.5} \mathrm{C}$ were constructed, as shown in Figure $1 \mathrm{a}, \mathrm{b}$, respectively. In Figure $1 \mathrm{a}$, the $\mathrm{B}_{6.5} \mathrm{C}$ structure, corresponding to $\mathrm{B}_{12}-\mathrm{CBC}$, with 13.33 at $\% \mathrm{C}$ is indicted as the most plausible structure for boron-rich boron carbide, in which $B_{12}$ denotes the icosahedron and the 3 -atom linear chain is $C-B-C$ [14]. The $B_{12}-C B C$ structure has the $R \overline{3} \mathrm{~m}$ space group. As shown in Figure $1 \mathrm{~b}$, the $\mathrm{B}_{2.5} \mathrm{C}$ structure, represented by $\mathrm{B}_{10} \mathrm{C}_{2}^{\mathrm{P}}-\mathrm{CC}$, at 28.57 at $\% \mathrm{C}$ is predicted to be the most stable configuration for carbon-rich boron carbide, where the icosahedral $C^{\mathrm{P}}$ atoms residing in the polar sites of the icosahedra without $C^{\mathrm{P}}-C^{\mathrm{P}}$ bonds and $\mathrm{C}-\mathrm{C}$ represent a diatomic carbon chain [11]. As mentioned in the introduction, the symmetry of $\mathrm{B}_{10} \mathrm{C}_{2}^{\mathrm{P}}-\mathrm{CC}$ structure is not $\mathrm{R} \overline{\mathrm{m}} \mathrm{m}$ because the $\mathrm{C}$ atoms substitute into $\mathrm{B}_{12}$ icosahedra, breaking its rhombohedral symmetry.

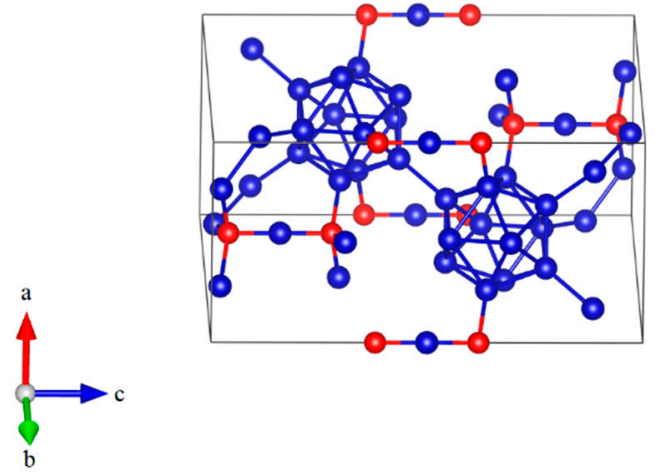

(a)

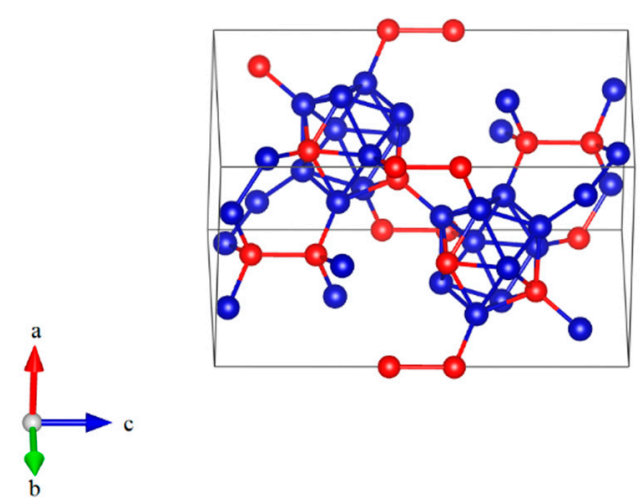

(b)

Figure 1. The atomic structures of boron- and carbon-rich boron carbide with hexagonal lattice: (a) $\mathrm{B}_{12}-\mathrm{CBC}$ configuration; (b) $\mathrm{B}_{10} \mathrm{C}_{2}^{\mathrm{P}}-\mathrm{CC}$ configuration (Blue $=\mathrm{B}$ atoms; red $=\mathrm{C}$ atoms).

The optimized equilibrium lattice parameters of $\mathrm{B}_{12}-\mathrm{CBC}$ and $\mathrm{B}_{10} \mathrm{C}_{2}^{\mathrm{P}}-\mathrm{CC}$ structures are listed in Table 1 and then compared with those of the $B_{11} C^{P}-C B C$ structure. Since a $B$ atom has a slightly larger atomic radius than $\mathrm{C}$ atom, the lattice parameters of boron carbide slightly expanded with the increase of boron content. It is consistent with experimental observation [2,21]. To confirm the thermodynamic stability of boron carbides, we computed the formation energy with respect to their constituent 
elements, given by $\alpha$-boron and graphite. The computed formation energy for $B_{12}-C B C, B_{11} C^{P}-C B C$ and $\mathrm{B}_{10} \mathrm{C}_{2}^{\mathrm{P}}-\mathrm{CC}$ is $-73.67,-116.56$ and $-72.64 \mathrm{meV} /$ atom, respectively. It means that these structures are thermodynamically stable crystal structures and can be synthesized by conventional methods. The value of formation energy can also represent the stability of the compounds. Thus, $\mathrm{B}_{11} \mathrm{C}^{\mathrm{P}}-\mathrm{CBC}$ presumably lies on the convex hull of the $\mathrm{B}-\mathrm{C}$ system because of its smallest formation energy.

Table 1. Lattice parameters of boron carbides.

\begin{tabular}{ccccccccc}
\hline Formula & Configuration & $\mathbf{\%} \mathbf{C}$ & $\mathbf{a}(\AA)$ & $\mathbf{b}(\AA)$ & $\mathbf{c}(\AA)$ & $\boldsymbol{\alpha}\left({ }^{\circ}\right)$ & $\boldsymbol{\beta}\left(^{\circ}\right)$ & $\gamma\left({ }^{\circ}\right)$ \\
\hline $\mathrm{B}_{6.5} \mathrm{C}$ & $\mathrm{B}_{12}-\mathrm{CBC}$ & 13.33 & 5.60 & 5.60 & 11.96 & 90.00 & 90.00 & 120.00 \\
$\mathrm{~B}_{4} \mathrm{C}^{1}$ & $\mathrm{~B}_{11} \mathrm{C}^{\mathrm{P}}-\mathrm{CBC}$ & 20.00 & 5.53 & 5.53 & 11.91 & 92.03 & 87.97 & 119.89 \\
$\mathrm{~B}_{2.5} \mathrm{C}$ & $\mathrm{B}_{10} \mathrm{C}_{2}^{\mathrm{P}}-\mathrm{CC}$ & 28.57 & 5.42 & 5.40 & 11.01 & 90.00 & 88.88 & 119.83 \\
\hline \multicolumn{7}{c}{ Ref. [25]. }
\end{tabular}

Then, elastic properties were calculated for each structure. The calculated elastic constants of boron carbides are shown in Table 2. The calculated elastic constants of these structures satisfied the Born stability criteria listed in Equation (1), suggesting that they are mechanically stable. In addition, the elastic properties of boron carbide have been shown to change with the carbon content. The isotropic polycrystalline elastic modulus, including bulk modulus (B), shear modulus (G), and Young's modulus (E), were estimated using the Voigt-Reuss-Hill (VRH) method [36], as shown in Table 3. The mechanical moduli are increased by increasing the carbon content in the structure. Thus, the general trend is that the strength of boron carbide decreases with lower carbon concentrations. Then, according to the relation between Vickers hardness $\left(\mathrm{H}_{\mathrm{V}}\right)$ and shear modulus proposed by Chen et al. [35], i.e., $\mathrm{H}_{\mathrm{V}}=0.151 \mathrm{G}$, which was shown to hold for many materials, the hardness of boron carbides can be estimated. As shown in Table 3, the hardness of $\mathrm{B}_{10} \mathrm{C}_{2}^{\mathrm{P}}-\mathrm{CC}$ is the highest among these structures because of its high shear modulus, indicating that the hardness of boron carbide increases with the carbon content.

Table 2. The calculated elastic constants Cij (GPa) of boron carbides using the stress-strain method.

\begin{tabular}{ccccccccc}
\hline Formula & Configuration & $\mathbf{\%} \mathbf{C}$ & $\mathbf{C}_{\mathbf{1 1}}$ & $\mathbf{C}_{\mathbf{1 2}}$ & $\mathbf{C}_{\mathbf{1 3}}$ & $\mathbf{C}_{\mathbf{1 4}}$ & $\mathbf{C}_{\mathbf{3 3}}$ & $\mathbf{C}_{\mathbf{4 4}}$ \\
\hline $\mathrm{B}_{5.6} \mathrm{C}^{1}$ & Experiment & 15.2 & 542.8 & 130.6 & 63.5 & $/$ & 534.5 & 164.8 \\
$\mathrm{~B}_{6.5} \mathrm{C}$ & $\mathrm{B}_{12}-\mathrm{CBC}$ & 13.33 & 526.7 & 142.5 & 83.1 & 10.5 & 465.3 & 99.2 \\
$\mathrm{~B}_{4} \mathrm{C}$ & $\mathrm{B}_{11} \mathrm{C}^{\mathrm{P}}-\mathrm{CBC}$ & 20.00 & 580.4 & 135.1 & 73.2 & 15.8 & 547.6 & 170.5 \\
$\mathrm{~B}_{2.5} \mathrm{C}$ & $\mathrm{B}_{10} \mathrm{C}_{2}^{\mathrm{P}}-\mathrm{CC}$ & 28.57 & 658.1. & 99.6 & 94.2 & -20.1 & 642.9 & 301.1 \\
$\mathrm{~B}_{2.5} \mathrm{C}^{2}$ & $\mathrm{~B}_{10} \mathrm{C}_{2}^{\mathrm{P}}-\mathrm{CC}$ & 28.57 & 620 & 90 & 75 & -23 & 605 & 290 \\
\hline \multicolumn{7}{c}{${ }^{1}$ Ref. [26], ${ }^{2}$ Ref. [11]. }
\end{tabular}

Table 3. The bulk modulus B (GPa), shear modulus G (GPa), Young's modulus E (GPa), Poisson ratio (v), Pugh's ductility index $(B / G)$, Vickers hardness $\left(\mathrm{H}_{V}\right)$ and anisotropy indexes $\left(\mathrm{A}^{\mathrm{U}}\right)$ of boron carbides calculated using the elastic constants, with the Voigt-Reuss-Hill (VRH) approximations applied for the evaluation of mechanical moduli.

\begin{tabular}{|c|c|c|c|c|c|c|c|c|c|c|c|c|c|}
\hline \multirow{2}{*}{ Formula } & \multirow{2}{*}{ Configuration } & \multirow{2}{*}{$\% \mathrm{C}$} & \multicolumn{3}{|c|}{ B } & \multicolumn{3}{|c|}{ G } & \multirow{2}{*}{ E } & \multirow{2}{*}{$\mathbf{v}$} & \multirow{2}{*}{$B_{H} / G_{H}$} & \multirow{2}{*}{$\mathbf{H}_{\mathbf{V}}$} & \multirow{2}{*}{$\mathbf{A}^{\mathbf{U}}$} \\
\hline & & & $\mathbf{B}_{\mathbf{V}}$ & $\mathbf{B}_{\mathbf{R}}$ & $\mathbf{B}_{\mathbf{H}}$ & $\mathrm{G}_{\mathrm{V}}$ & $\mathrm{G}_{\mathrm{R}}$ & $\mathrm{G}_{\mathrm{H}}$ & & & & & \\
\hline $\mathrm{B}_{5,6} \mathrm{C}^{1}$ & Experiment & 15.2 & / & / & 237 & / & / & 195 & 460 & 0.18 & 1.22 & 29.4 & / \\
\hline $\mathrm{B}_{6.5} \mathrm{C}$ & $\mathrm{B}_{12}-\mathrm{CBC}$ & 13.33 & 237.3 & 238.1 & 237.7 & 158.8 & 141.2 & 150.0 & 371.6 & 0.24 & 1.58 & 22.7 & 0.62 \\
\hline $\mathrm{B}_{4} \mathrm{C}$ & $\mathrm{B}_{11} \mathrm{C}^{\mathrm{P}}-\mathrm{CBC}$ & 20.00 & 255.0 & 252.9 & 253.9 & 207.7 & 198.2 & 202.9 & 480.7 & 0.18 & 1.25 & 30.6 & 0.25 \\
\hline $\mathrm{B}_{2.5} \mathrm{C}$ & $\mathrm{B}_{10} \mathrm{C}_{2}^{\mathrm{P}}-\mathrm{CC}$ & 28.57 & 279.1 & 277.8 & 278.4 & 285.9 & 285.7 & 285.8 & 638.8 & 0.12 & 0.97 & 43.2 & 0.01 \\
\hline
\end{tabular}

Generally, the Pugh's ductility indexes $(B / G)$ is frequently used to indicate the ductility of compounds [24,37]. It is supposed that for brittle compounds, $B / G$ is smaller than 1.75 (for diamond $\mathrm{B} / \mathrm{G}=0.8$ ) and for metallic compounds, $\mathrm{B} / \mathrm{G}$ is greater than 1.75 (for $\mathrm{Al} \mathrm{B} / \mathrm{G}=2.74$ ) [37]. As shown in 
Table 3, the Pugh's ductility index for $\mathrm{B}_{12}-\mathrm{CBC}, \mathrm{B}_{11} \mathrm{C}^{\mathrm{P}}-\mathrm{CBC}$ and $\mathrm{B}_{10} \mathrm{C}_{2}^{P}-\mathrm{CC}$ are all smaller than 1.75 , suggesting that these structures are brittle materials. Among these structures, the Pugh's ductility indexes for $\mathrm{B}_{10} C_{2}^{P}-\mathrm{CC}$ is the smallest, indicating that the toughness of $\mathrm{B}_{10} C_{2}^{P}-\mathrm{CC}$ is the lowest among these boron carbides. Moreover, anisotropy index $\mathrm{A}^{\mathrm{U}}$, which is a new universal anisotropy indexes given by Ranganathan et al. [34], can be calculated by $A^{U}=5 G_{V} / G_{R}+B_{V} / B_{R}-6$, and could be used to characterize the anisotropy in elasticity of boron carbides. A value of unity means that the crystal exhibits isotropic properties, while values otherwise represent varying degrees of anisotropy. As shown in Table 3, although $B_{12}-C B C$ has the highest symmetry among these structures, it also suffers from the strongest anisotropy. This character can also be found in titanium borides compounds [37].

\subsection{Stress-Strain Relationship}

\subsubsection{Hydrostatic Compression}

The results of hydrostatic compression on $\mathrm{B}_{12}-\mathrm{CBC}, \mathrm{B}_{11} \mathrm{C}^{\mathrm{P}}-\mathrm{CBC}$ and $\mathrm{B}_{10} \mathrm{C}_{2}^{\mathrm{P}}-\mathrm{CC}$ are shown in Figure 2, where the volume strain and total energy are plotted with the hydrostatic pressure. As displayed in Figure 2a, under the same hydrostatic pressure, the volume strain for $B_{10} C_{2}^{P}-C C$ is the smallest among these structures due to its highest bulk modulus. In Figure $2 a, b$, the volume strain and total energy vary continuously and smoothly in all models even when the hydrostatic pressure increases to $320 \mathrm{GPa}$.This agrees with previous theoretical calculations $[27,38]$.
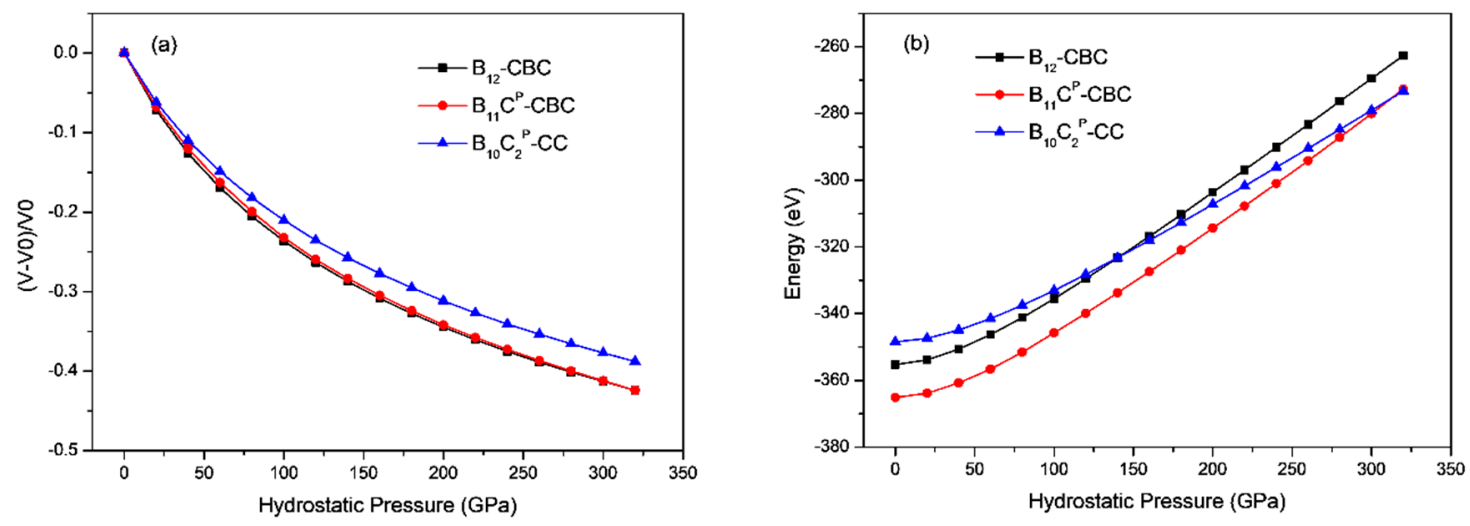

Figure 2. (a) The volume strain vs. hydrostatic pressure (b) the total energy vs. hydrostatic pressure in $\mathrm{B}_{12}-\mathrm{CBC}, \mathrm{B}_{11} \mathrm{C}^{\mathrm{P}}-\mathrm{CBC}$ and $\mathrm{B}_{10} \mathrm{C}_{2}^{\mathrm{P}}-\mathrm{CC}$ configurations. The volume strain and total energy varies continuously.

\subsubsection{Uniaxial Compressions}

The stress-strain curves for uniaxial compression along the $c$ axis and the $a$ axis of $\mathrm{B}_{12}-\mathrm{CBC}$ and $\mathrm{B}_{10} \mathrm{C}_{2}^{\mathrm{P}}-\mathrm{CC}$ structures are displayed in Figures 3 and 4 , respectively, and compared with the results of the regular $\mathrm{B}_{11} \mathrm{C}^{\mathrm{P}}-\mathrm{CBC}$ crystal [25]. In Figures 3 and 4, there are several abrupt points in the stress-strain curves for these structures. To further investigate the deformation behaviors related to these abrupt points, the strain increment was changed from $1 \%$ to $0.2 \%$ in these regions. As shown in Figure 3, the maximum stress for on $\mathrm{B}_{12}-\mathrm{CBC}$ and $\mathrm{B}_{10} \mathrm{C}_{2}^{\mathrm{P}}-\mathrm{CC}$ are $145.46 \mathrm{GPa}$ and $127.87 \mathrm{GPa}$, respectively, which is lower than the strength limit of $\mathrm{B}_{11} \mathrm{C}^{\mathrm{P}}-\mathrm{CBC}(172.18 \mathrm{GPa})$. 


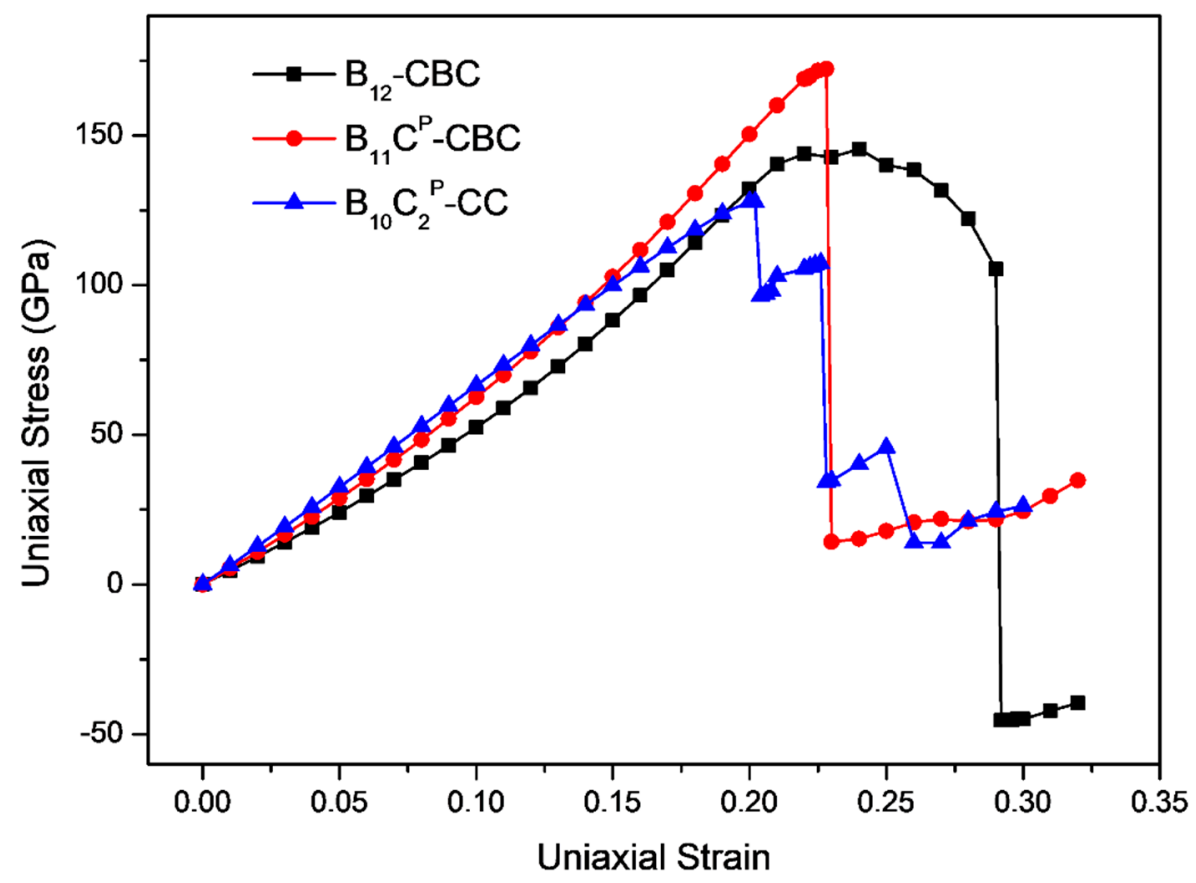

Figure 3. The stress-strain curves for on $\mathrm{B}_{12}-\mathrm{CBC}, \mathrm{B}_{11} \mathrm{C}^{\mathrm{P}}-\mathrm{CBC}$ and $\mathrm{B}_{10} \mathrm{C}_{2}^{\mathrm{P}}-\mathrm{CC}$ configurations under $c$ axis uniaxial compression.

In Figure 3, the stresses initially increase almost linearly up to the maximum stress, indicating that these structures are uniformly resistant to the deformation. Then, for the $\mathrm{B}_{12}-\mathrm{CBC}$ structure, the stress varies continuously from its maximum stress (145.46 GPa at $\varepsilon=0.24$ ) to 105.38 GPa with $\varepsilon=0.29$ without structural changes. Finally, at $\varepsilon=0.292$, an abrupt drop in stress to -45.37 GPa occurs, suggesting that the $\mathrm{B}_{12}-\mathrm{CBC}$ structure is destroyed. However, for the $\mathrm{B}_{10} \mathrm{C}_{2}^{\mathrm{P}}-\mathrm{CC}$ structure, beyond the maximum stress, there is a first sudden stress drop to $96.46 \mathrm{GPa}$ with $\varepsilon=0.204$ then the stress increases continuously. As the strain increases, the stress ultimately drops to $34.21 \mathrm{GPa}$ at $\varepsilon=0.228$, and then appears to fluctuate, indicating that the $\mathrm{B}_{10} \mathrm{C}_{2}^{\mathrm{P}}-\mathrm{CC}$ structure is under destruction. Under $c$ axis compression, the critical failure strain for $\mathrm{B}_{12}-\mathrm{CBC}, \mathrm{B}_{11} \mathrm{C}^{\mathrm{P}}-\mathrm{CBC}$ and $\mathrm{B}_{10} \mathrm{C}_{2}^{\mathrm{P}}-\mathrm{CC}$ is $0.292,0.23$ and 0.228 , respectively, suggesting that the $\mathrm{B}_{10} C_{2}^{\mathrm{P}}-\mathrm{CC}$ is the most brittle structure among these configurations.

For uniaxial compression along $a$ axis, as displayed in Figure 4, the maximum stress for $\mathrm{B}_{10} \mathrm{C}_{2}^{\mathrm{P}}-\mathrm{CC}$ is $97.79 \mathrm{GPa}$, which is higher than that of $\mathrm{B}_{12}-\mathrm{CBC}(91.67 \mathrm{GPa})$ and $\mathrm{B}_{11} \mathrm{C}^{\mathrm{P}}-\mathrm{CBC}(89.04 \mathrm{GPa})$. For the $B_{12}-C B C$ structure, as the strain increases to 0.148 , the stress increases continuously, indicating that the structure deforms elastically. At $\varepsilon=0.15$, similarly to $\mathrm{B}_{11} \mathrm{C}^{\mathrm{P}}-\mathrm{CBC}$ structure, there is a small stress fluctuation before reaching the maximum stress. Then the stress monotonically increases until it reaches the maximum stress of $91.67 \mathrm{GPa}$ at $\varepsilon=0.234$. After that, the stress decreases slightly from 91.67 GPa to $90.20 \mathrm{GPa}$ at $\varepsilon=0.238$. At $\varepsilon=0.24$, the stress drops suddenly to $55.98 \mathrm{GPa}$. Finally, the stress drops again to $11.89 \mathrm{GPa}$ at $\varepsilon=0.256$. While for $\mathrm{B}_{10} \mathrm{C}_{2}^{\mathrm{P}}-\mathrm{CC}$ structure, unlike the $\mathrm{B}_{12}-\mathrm{CBC}$ and $\mathrm{B}_{11} \mathrm{C}^{\mathrm{P}}-\mathrm{CBC}$ structures, the stress increases almost linearly and monotonically until reaching the maximum stress of $97.79 \mathrm{GPa}$ at $\varepsilon=0.15$. Beyond the point of maximum stress, the stress decreases generally. At compressive strain $\varepsilon=0.152$, there is a sudden drop in stress to $65.97 \mathrm{GPa}$. Then, the stress drops again to $49.65 \mathrm{GPa}$ at $\varepsilon=0.158$. Finally, the stress ultimately drops to a minimum value $32.88 \mathrm{GPa}$ with $\varepsilon=0.17$. Under $a$ axis compression, the critical failure strain for $\mathrm{B}_{12}-\mathrm{CBC}, \mathrm{B}_{11} \mathrm{C}^{\mathrm{P}}-\mathrm{CBC}$ and $\mathrm{B}_{10} \mathrm{C}_{2}^{\mathrm{P}}-\mathrm{CC}$ is $0.256,0.23$ and 0.17 , respectively, indicating that the toughness of the $\mathrm{B}_{10} \mathrm{C}_{2}^{\mathrm{P}}-\mathrm{CC}$ structure is the lowest among these structures under $a$ axis compression. 


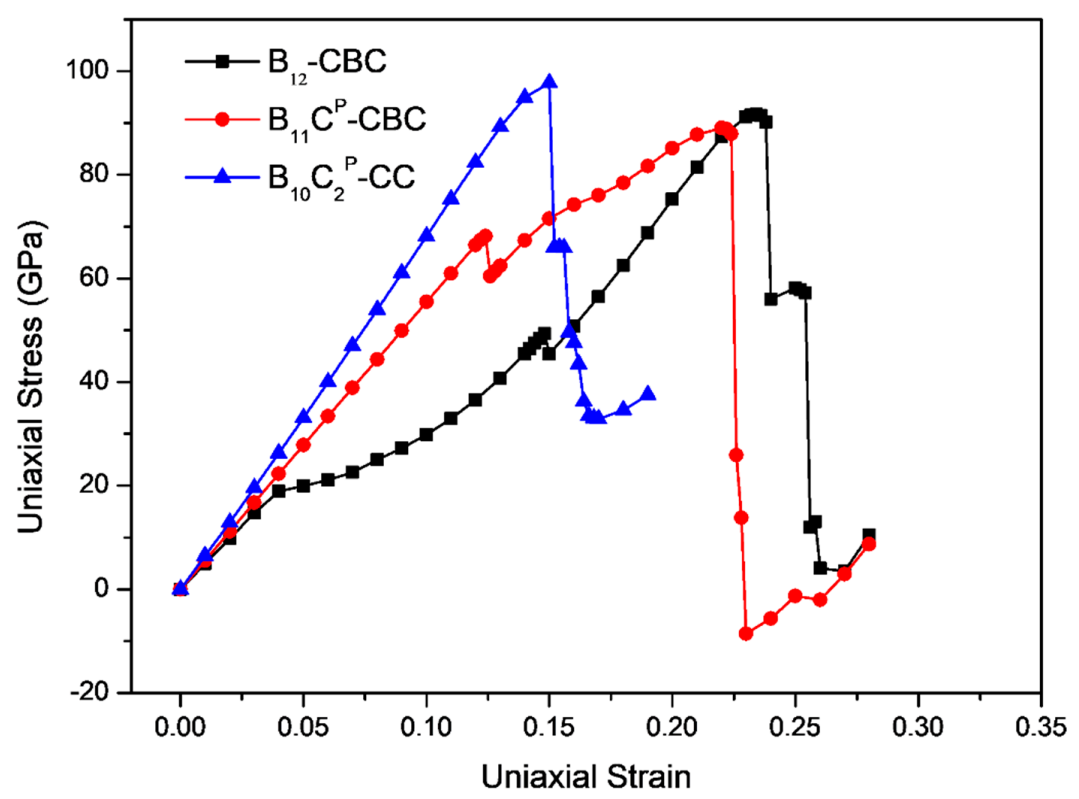

Figure 4. The stress-strain relationships for on $B_{12}-C B C, B_{11} C^{P}-C B C$ and $B_{10} C_{2}^{P}-C C$ configurations under $a$ axis uniaxial compression.

The above results indicate that the mechanical behaviors and deformation processes of $\mathrm{B}_{12}-\mathrm{CBC}$ and $\mathrm{B}_{10} \mathrm{C}_{2}^{\mathrm{P}}-\mathrm{CC}$ structures for uniaxial compression along $c$ axis and $a$ axis are very different, mainly because of the anisotropy of the $\mathrm{B}_{12}-\mathrm{CBC}$ and $\mathrm{B}_{10} \mathrm{C}_{2}^{\mathrm{P}}-\mathrm{CC}$ structures. To explain the underlying anisotropic deformation mechanism, structural changes and the isosurface of the electron localization function (ELF) in $\mathrm{B}_{12}-\mathrm{CBC}$ and $\mathrm{B}_{10} \mathrm{C}_{2}^{\mathrm{P}}-\mathrm{CC}$ are further studied. It is a reliable way to analyze the lone pair formation and covalent bonding [39-41].

\subsection{Anisotropic Deformation Mechanism}

\subsection{1. c Axis Compression}

To understand the deformation behaviors of $\mathrm{B}_{12}-\mathrm{CBC}$ under $\mathrm{c}$ axis compression, structural changes in the $B_{12}-C B C$ structure were examined, as displayed in Figure 5. Figure 5a shows the undeformed structure of $B_{12}-C B C$. As the compressive strain increases to 0.29 , the structure deforms elastically. The $\mathrm{C}-\mathrm{B}-\mathrm{C}$ chains are still straight and the icosahedra are intact, but deformed slightly, as shown in Figure $5 b$,c. At compressive strain $\varepsilon=0.292$ (Figure $5 d$ ), the $B_{12}$ icosahedra are fully destroyed without bending the $\mathrm{C}-\mathrm{B}-\mathrm{C}$ chains, leading to a sudden drop in stress to a negative value (Figure 3 ). Thus, the main reason for the structural failure of $\mathrm{B}_{12}-\mathrm{CBC}$ structure is the destruction of icosahedra.
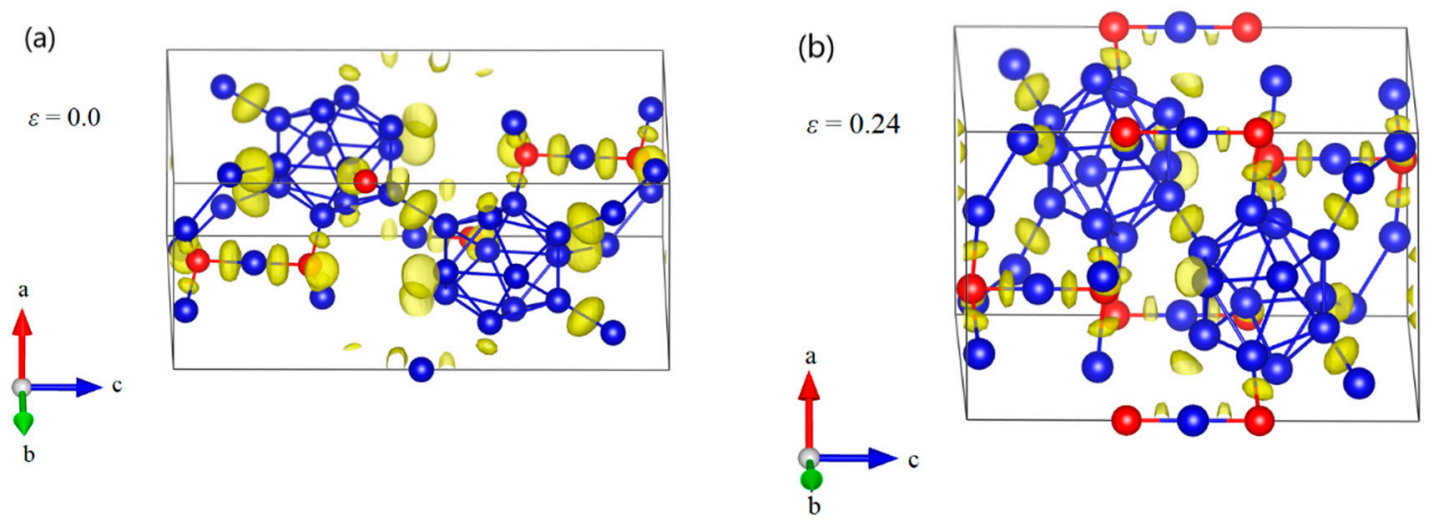

Figure 5. Cont. 
(c)

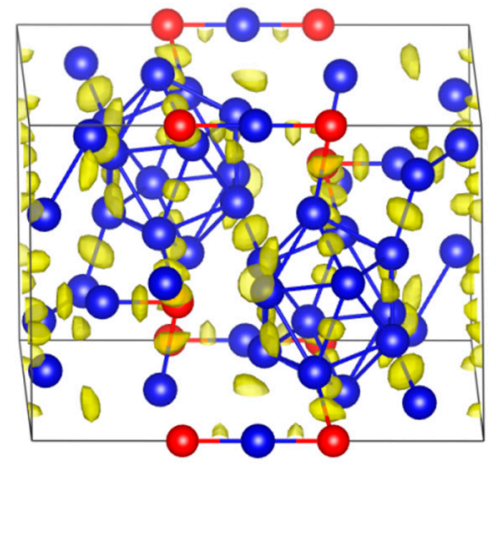

(d)

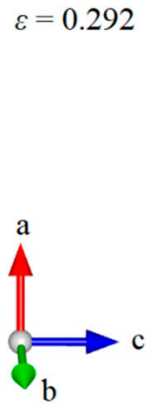

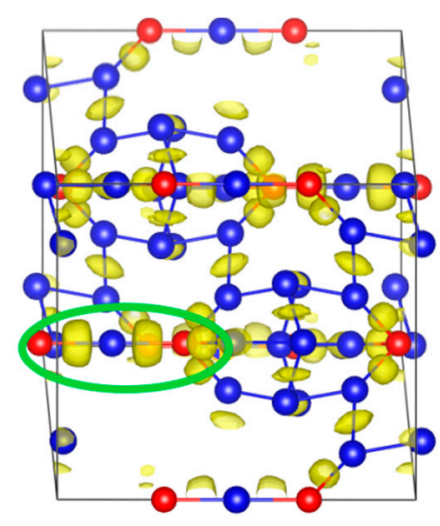

Figure 5. The structural changes and electron localization function (ELF) at various critical strains for $\mathrm{B}_{12}-\mathrm{CBC}$ structure under $c$ axis compression: (a) the undeformed structure; (b) the structure at $\varepsilon=0.24$ relating to the maximum stress; (c) the structure at $\varepsilon=0.29$ before structural failure, where the chains are still straight and the icosahedra are intact; (d) the structure at $\varepsilon=0.292$ where the structure fails because the icosahedra are fully destroyed without bending the $\mathrm{C}-\mathrm{B}-\mathrm{C}$ chains (Blue $=\mathrm{B}$ atoms; red $=\mathrm{C}$ atoms).

However, the deformation behaviors for the $\mathrm{B}_{10} \mathrm{C}_{2}^{\mathrm{P}}-\mathrm{CC}$ structure are more complicated than that of $B_{12}-C B C$, as shown in Figure 6. Figure 6a displays the undeformed structure of $B_{10} C_{2}^{P}-C C$. As the compressive strain increases to 0.202 , the structure uniformly resists the elastic deformation and the icosahedra are intact without breaking any bonds (Figure $6 \mathrm{~b}, \mathrm{c}$ ). At compressive strain $\varepsilon=0.204$ (Figure $6 \mathrm{~d}$ ), one of the $\mathrm{B}-\mathrm{C}^{\mathrm{P}}$ bonds within the icosahedron stretches from the original $1.666 \AA$ to $2.302 \AA$, indicating that the $\mathrm{B}_{10} \mathrm{C}_{2}^{\mathrm{P}}-\mathrm{CC}$ icosahedra begin to be destroyed. At the same time, the diatomic carbon chains are no longer parallel to the $c$ axis but there is no new bond formed. Thus, the first sudden stress drops in the $\mathrm{B}_{10} \mathrm{C}_{2}^{\mathrm{P}}$-CC structure mainly results from the breakage of $\mathrm{B}-\mathrm{C}^{\mathrm{P}}$ bonds within icosahedra. Then, the stress monotonically increases from $96.46 \mathrm{GPa}$ to $107.45 \mathrm{GPa}$ at $\varepsilon=0.228$ without totally destroying the $\mathrm{B}_{10} \mathrm{C}_{2}^{\mathrm{P}}-\mathrm{CC}$ icosahedra. The icosahedra are highly disordered but still identifiable (Figure 6e). As displayed in Figure $6 \mathrm{f}$, the $\mathrm{B}_{10} \mathrm{C}_{2}^{\mathrm{P}}-\mathrm{CC}$ icosahedra are fully destroyedabove compressive strain of 0.26 , causing the stress to fluctuate up and down without any patterns. The $\mathrm{B}_{10} \mathrm{C}_{2}^{\mathrm{P}}-\mathrm{CC}$ structure is fully destroyed.

(a)
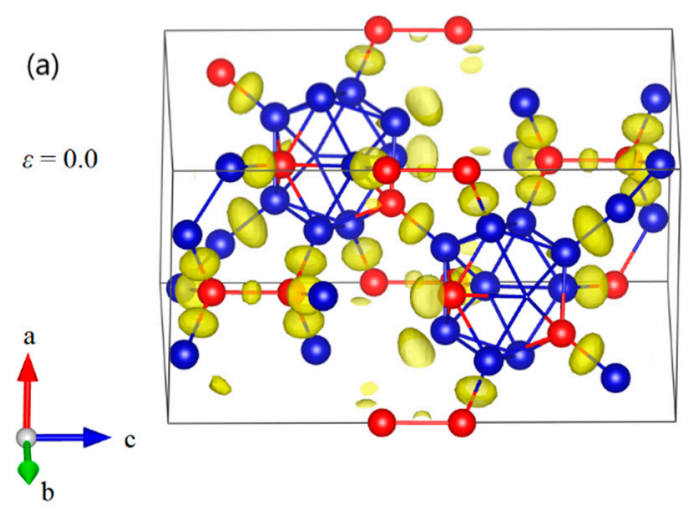

(b)

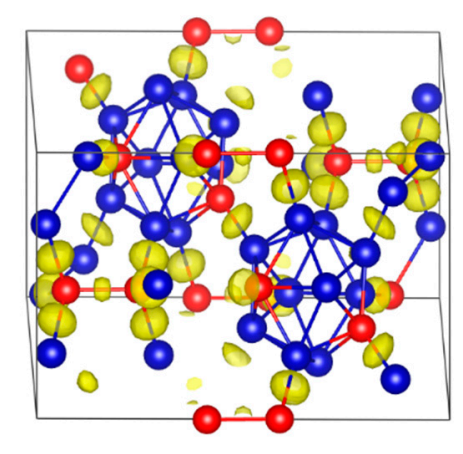

Figure 6. Cont. 

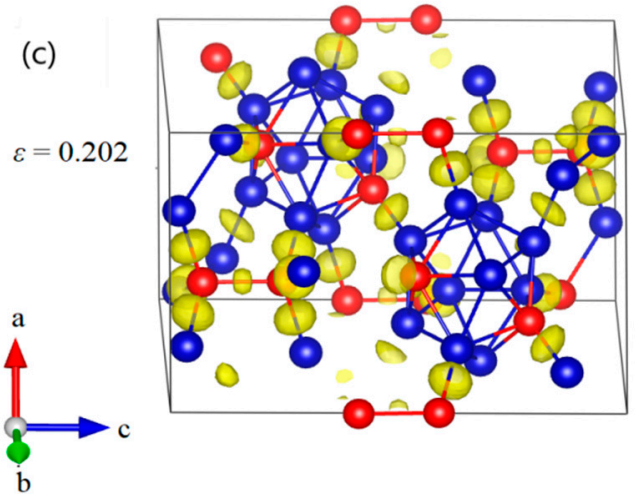

(e)
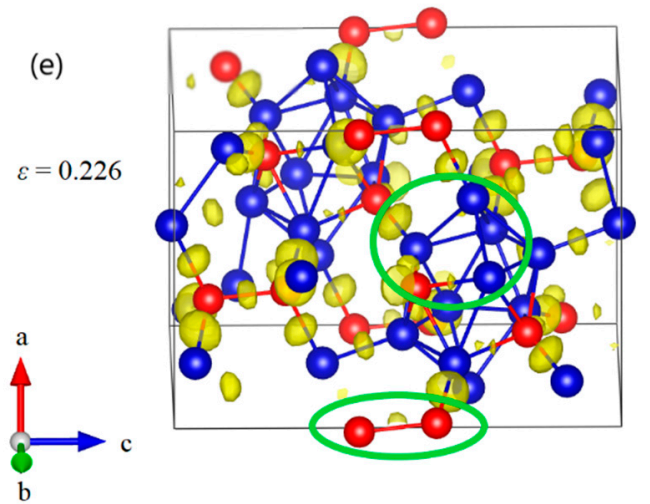

(d)
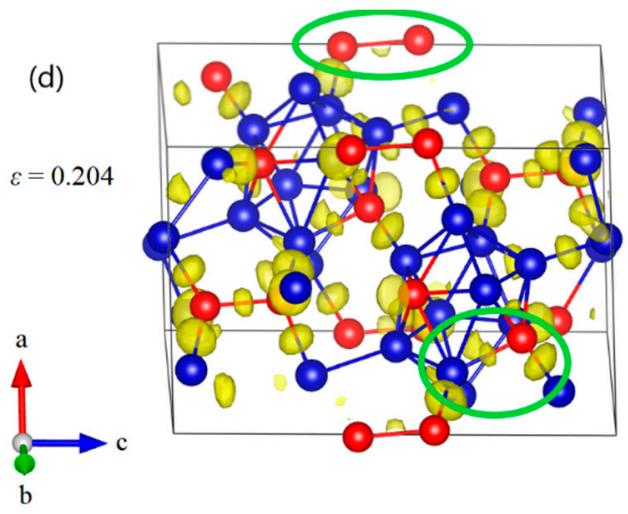

(f)

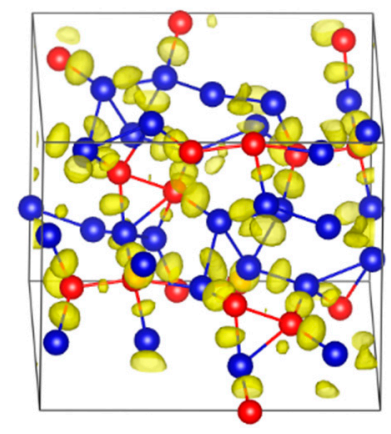

Figure 6. The structural changes and ELF at various critical strains for $\mathrm{B}_{10} \mathrm{C}_{2}^{\mathrm{P}}-\mathrm{CC}$ structure under $c$ axis uniaxial compression: (a) the initial structure; (b) the structure at $\varepsilon=0.20$ relating to the maximum stress; (c) the structure at $\varepsilon=0.202$ before the first stress drop, where the icosahedra are intact without breaking any bonds; (d) the structure at $\varepsilon=0.204$ after the first stress drop, where the $\mathrm{B}-\mathrm{C}^{\mathrm{P}}$ bonds within icosahedra are broken; (e) the structure at $\varepsilon=0.226$ before structural failure; ( $\mathbf{f}$ ) the structure at $\varepsilon=0.228$ where the structure fails because of the fully destruction of icosahedra (Blue $=\mathrm{B}$ atoms; red $=\mathrm{C}$ atoms).

\subsection{2. a Axis Compression}

Since $\mathrm{B}_{11} \mathrm{C}^{\mathrm{P}}-\mathrm{CBC}$ has strong anisotropic elasticity, interatomic bonding, and deformation behaviors [25-27], it is also necessary to understand the compression deformation mechanisms for $\mathrm{B}_{12}-\mathrm{CBC}$ and $\mathrm{B}_{10} \mathrm{C}_{2}^{\mathrm{P}}-\mathrm{CC}$ under different loading directions. The structural changes of $\mathrm{B}_{12}-\mathrm{CBC}$ and $\mathrm{B}_{10} \mathrm{C}_{2}^{\mathrm{P}}-\mathrm{CC}$ under $a$ axis uniaxial compression were examined, as displayed in Figures 7 and 8 . As shown in Figure $7 \mathrm{a}$, the $\mathrm{B}_{12}-\mathrm{CBC}$ structure uniformly resists the elastic deformation until the compressive strain reaches 0.148 . The $C-B-C$ chains are almost straight and the icosahedra are intact. Then at $\varepsilon=0.15$, the $\mathrm{B}$ atoms in the chain center form new B-B bonds with the B atoms in neighboring icosahedra, causing a small stress fluctuation, as displayed in Figure $7 \mathrm{~b}$. In this process, the angle of chains decreases suddenly from $179.9^{\circ}$ to $129.2^{\circ}$, while the icosahedra remain intact and deform slightly. To further explain the deformation behavior of the $\mathrm{B}_{12}-\mathrm{CBC}$ structure at $\varepsilon=0.15$, unloading calculations were performed. As illustrated in Figure 9, the 3-atom chains remain bending after unloading from $\varepsilon=0.15$, implying an unrecoverable deformation occurs on $\mathrm{B}_{12}-\mathrm{CBC}$ structure at this strain level. After that, the stress monotonically increases to the maximum value of 91.67 GPa at $\varepsilon=0.234$. Then, at compressive strain $\varepsilon=0.238$ (before the first stress drop), there is a slight decrease in stress from 91.67 GPa to 90.2 GPa. However, the icosahedra are still identifiable and intact, as displayed in Figure $7 c$. In Figure $7 d$, the $B_{12}-C B C$ structure is partly broken, so that only one icosahedron is in destruction, causing a first sudden drop in stress to $55.98 \mathrm{GPa}$ at $\varepsilon=0.24$. Then, as the compressive strain further increases to 0.254 (before the second stress drop), the stress varies continually to $57.18 \mathrm{GPa}$, without totally destroying the structure (Figure 7e). Finally, as shown in Figure 7f, the icosahedra and 
the structure are fully destroyed at compressive strain $\varepsilon=0.256$, causing the stress to fluctuate up and down without any patterns.
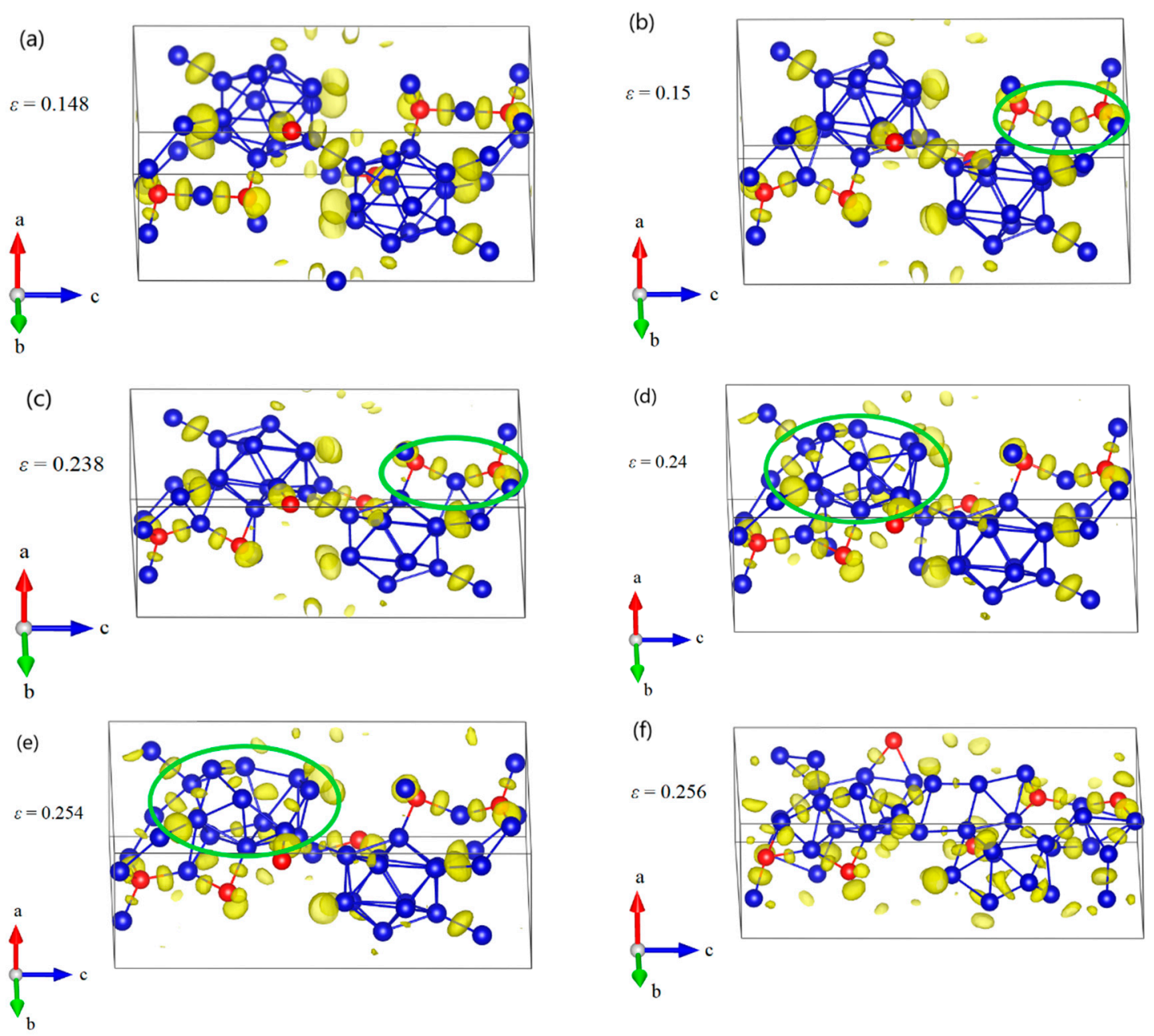

Figure 7. The structural changes and ELF at various critical strains for $\mathrm{B}_{12}-\mathrm{CBC}$ structure under $a$ axis uniaxial compression: (a) the structure at $\varepsilon=0.148$ where it uniformly resists the elastic deformation and the $\mathrm{C}-\mathrm{B}-\mathrm{C}$ chains are almost straight; (b) the structure at $\varepsilon=0.15$ where some new $\mathrm{B}-\mathrm{B}$ bonds are formed, leading to a small stress fluctuation; (c) the structure at $\varepsilon=0.238$ before the first significant stress drop where the icosahedra are identifiable and intact; (d) the structure at $\varepsilon=0.24$ after the first stress drop, where one of the icosahedra are broken. (e) the structure at $\varepsilon=0.254$ before structural failure; (f) the structure at $\varepsilon=0.256$ where the icosahedra and the structure are fully destroyed (Blue $=\mathrm{B}$ atoms; red $=$ C atoms).

The structural changes of $\mathrm{B}_{10} \mathrm{C}_{2}^{\mathrm{P}}-\mathrm{CC}$ structure under $a$ axis compression are displayed in Figure 8 . As the compressive strain increases to 0.15 , the icosahedra are intact but slightly deformed (Figure 8a,b). Then one of the $\mathrm{B}-\mathrm{C}^{\mathrm{P}}$ bonds within the icosahedron increases from the original $1.792 \AA$ to $2.639 \AA$ at $\varepsilon=0.152$, causing a sudden drop in stress to $65.97 \mathrm{GPa}$ (Figure $8 \mathrm{c}$ ). The $\mathrm{B}_{10} \mathrm{C}_{2}^{\mathrm{P}}-\mathrm{CC}$ icosahedra begin to be destroyed. At $\varepsilon=0.158$ (Figure $8 \mathrm{~d}$ ), all $\mathrm{B}-\mathrm{C}^{\mathrm{P}}$ bonds within icosahedra are broken, leading to the second sudden stress drop to $49.65 \mathrm{GPa}$. In this process, the icosahedra are not intact, but still identifiable. After that, in Figure 8e, the icosahedra are gradually destroyed, resulting in the monotonic decrease in stress (Figure 4). Finally, the structure fails, due to the fully destruction of icosahedra, as shown in Figure 8f. 
(a)
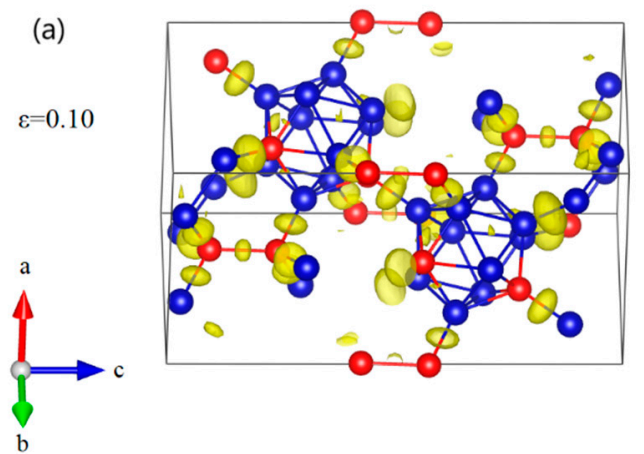

(c) $\varepsilon=0.15$<smiles>CCCCCCCC</smiles>

(e)
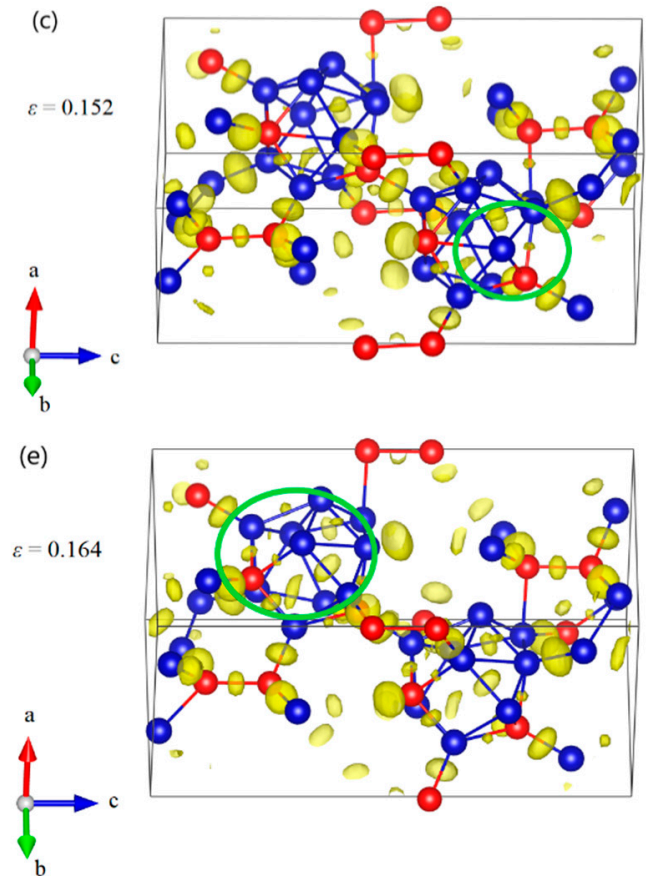

(b)
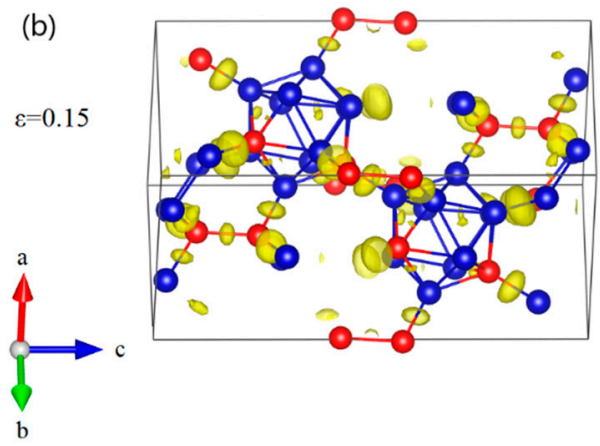

(d)

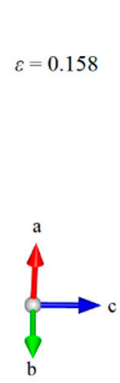

(f)

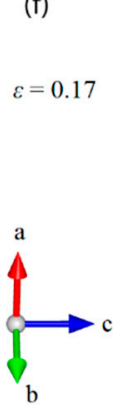

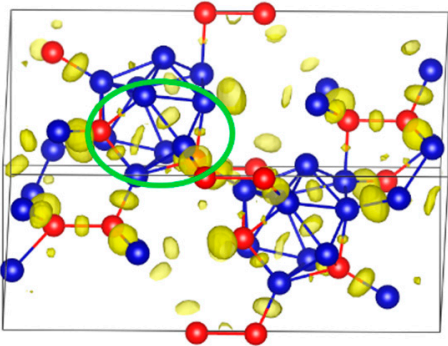

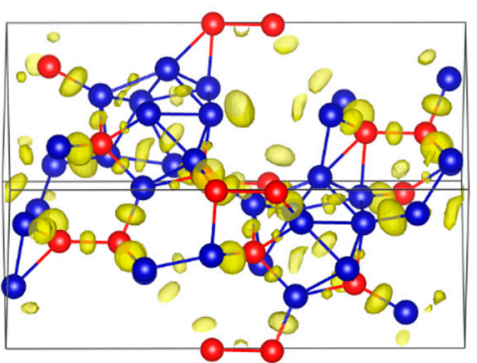

Figure 8. The structural changes and ELF at various critical strains for $\mathrm{B}_{10} \mathrm{C}_{2}^{\mathrm{P}}-\mathrm{CC}$ structure under $a$ axis uniaxial compression: (a) the structure at $\varepsilon=0.10$ in elastic deformation stage; (b) the structure at $\varepsilon=0.15$ relating to the maximum stress, where the icosahedra are intact; (c) the structure at $\varepsilon=0.152$ after the first stress drop, where one of the $\mathrm{B}-\mathrm{C}^{\mathrm{P}}$ bonds within the icosahedron is broken; (d) the structure at $\varepsilon=0.158$ after the second stress drop, where all $\mathrm{B}-\mathrm{C}^{\mathrm{P}}$ bonds within icosahedra are broken; (e) the structure at $\varepsilon=0.164$, where the icosahedra are gradually damaged; ( $f$ ) the structure at $\varepsilon=0.17$ where the structure fails due to the fully destruction of icosahedra (Blue = B atoms; red $=\mathrm{C}$ atoms).

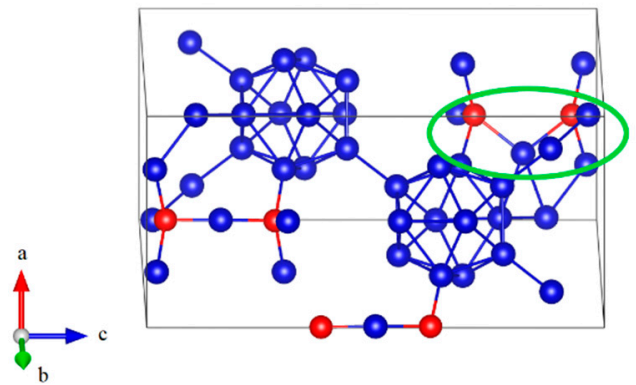

Figure 9. The structure after unloading from $\varepsilon=0.15$ for $\mathrm{B}_{12}-\mathrm{CBC}$ structure under $a$ axis uniaxial compression, where the 3-atom chain remain bending, implying an unrecoverable deformation occurs (Blue $=\mathrm{B}$ atoms; red $=\mathrm{C}$ atoms). 


\section{Discussion}

In our work, three stable configurations of boron carbide, represented by $\mathrm{B}_{12}-\mathrm{CBC}(13.33$ at \% $\mathrm{C})$, $\mathrm{B}_{11} \mathrm{C}^{\mathrm{P}}-\mathrm{CBC}(20.0$ at $\% \mathrm{C})$ and $\mathrm{B}_{10} \mathrm{C}_{2}^{\mathrm{P}}-\mathrm{CC}(28.75$ at $\% \mathrm{C})$, were used to investigate the effects of carbon content on the mechanical properties and anisotropic deformation mechanisms of boron carbide. The results have shown that atomic structure and carbon content have an obvious effect on the structural properties and mechanical properties of boron carbides. As displayed in Table 1, the lattice parameters of boron carbides slightly expanded with the increases of boron content, due to the different atomic radius between $B$ and $C$ atoms. Since the substitution of $C$ atoms in the icosahedra induces a small distortion, only the $\mathrm{B}_{12}-\mathrm{CBC}$ structure has the $\mathrm{R} \overline{\mathrm{z}} \mathrm{m}$ space group. In addition, the elastic properties of boron carbide have been found to change with the carbon content. As shown in Table 3, the strength and the hardness of boron carbide increase with the increasing of carbon content. The Pugh's ductility index implies that all structures exhibit brittle behaviors, and the toughness of $B_{10} C_{2}^{\mathrm{P}}-C C$ is lowest among these structures. Moreover, $\mathrm{B}_{10} \mathrm{C}_{2}^{\mathrm{P}}-\mathrm{CC}$ also suffers from the weakest anisotropy, because of its lowest anisotropy indexes. These results agree well with previous experimental and theoretical studies $[1,2,15,21]$.

For all structures under hydrostatic compression, continuous changes in volume strain and total energy were observed up to a very high hydrostatic pressure of $320 \mathrm{eV}$. However, when compressed along $c$ axis or $a$ axis direction, the structures underwent massive structural changes and final failure. Under uniaxial compressions, the strength is significantly overestimated in comparison with other experiments [5,42]. One possible reason is that the perfect crystal structure of boron carbides was considered in our work. Thus, the role of defects such as point defects, crystal impurity and microcracks on the deformation mechanism of boron carbide was omitted. But it is almost impossible to obtain such perfect crystal structures in experiments. Another reason is the use of ionic relaxation at zero temperature in the first-principles calculations. Computational results have also suggested that the maximum stress along the $c$ axis is much larger than that of the $a$ axis, indicating that the strength of the boron carbide crystal is higher along the [0001] direction. However, it should be noted that $\mathrm{C}_{11}$ is higher than $\mathrm{C}_{33}$ for the $\mathrm{B}_{12}-\mathrm{CBC}, \mathrm{B}_{11} \mathrm{C}^{\mathrm{P}}-\mathrm{CBC}$ and $\mathrm{B}_{10} \mathrm{C}_{2}^{\mathrm{P}}-\mathrm{CC}$ structural configurations. This apparent contradiction may be in terms of internal relaxation of the boron carbide lattice under external stress [43], and the instability of atom chains under perpendicular loading. Although the $\mathrm{B}_{10} \mathrm{C}_{2}^{\mathrm{P}}-\mathrm{CC}$ structure has the largest elastic moduli, the breakage of $\mathrm{B}-\mathrm{C}^{\mathrm{P}}$ bonds within icosahedra at 0.204 strain releases its stress under $c$ axis compression, decreasing its maximum strength below that of the $\mathrm{B}_{11} \mathrm{C}^{\mathrm{P}}-\mathrm{CBC}$ and $\mathrm{B}_{12}-\mathrm{CBC}$ structures. And the results also imply that the toughness of $\mathrm{B}_{10} \mathrm{C}_{2}^{\mathrm{P}}-\mathrm{CC}$ which has the smallest Pugh's ductility index, is the lowest among these configurations, because of its lowest failure strain.

In addition, the effects of carbon content on the anisotropic deformation mechanism for boron carbide were further examined. For the $\mathrm{B}_{12}-\mathrm{CBC}$ structure with 13.33 at $\% \mathrm{C}$, under $c$ axis compression, the destruction of icosahedra without bending $\mathrm{C}-\mathrm{B}-\mathrm{C}$ chains is the main mechanism for structural failure; while under $a$ axis compression, the new B-B bonds between chains and icosahedra are formed, resulting in a small stress fluctuation before reaching the maximum stress. In the process, an unrecoverable deformation occurs. Then, the structure is gradually destroyed, causing the two sudden drops in stress. Finally, the icosahedra and the structure are fully destroyed. For the $\mathrm{B}_{11} \mathrm{C}^{\mathrm{P}}-\mathrm{CBC}$ structure with 20.0 at $\%$ C [25], the deformation mechanism is related to the formation of new B-B bonds between chains and icosahedra for $c$ axis compression and the destruction of icosahedra for $a$ axis compression. We should note that for the $\mathrm{B}_{11} \mathrm{C}^{\mathrm{P}}-\mathrm{CBC}$ structure, there is also a small stress fluctuation in the elastic deformation stage results from abrupt bending of $\mathrm{C}-\mathrm{B}-\mathrm{C}$ chains without forming new bonds. The different deformation mechanisms between $B_{12}-C B C$ and $B_{11} C^{P}-C B C$ structures maybe results from the $C$ atom in the icosahedra, which breaks the rhombohedral symmetry $(\mathrm{R} \overline{3} \mathrm{~m})$ of $\mathrm{B}_{11} \mathrm{C}^{\mathrm{P}}-\mathrm{CBC}$ structure.

However, for $\mathrm{B}_{10} \mathrm{C}_{2}^{\mathrm{P}}-\mathrm{CC}$ structure with 28.75 at $\% \mathrm{C}$, whose anisotropy indexes $\mathrm{A}^{\mathrm{U}}$ is the lowest, the deformation mechanism for compression along the $a$ axis and $c$ axis directions is slightly different. 
Under $c$ axis compression, the breakage of one of the $\mathrm{B}-\mathrm{C}^{\mathrm{P}}$ bonds with the icosahedron results in the first stress drop in the $\mathrm{B}_{10} \mathrm{C}_{2}^{\mathrm{P}}-\mathrm{CC}$ structure. And then the structure can sustain the further compressive deformations without totally destroying the $\mathrm{B}_{10} \mathrm{C}_{2}^{\mathrm{P}}-\mathrm{CC}$ icosahedra. Finally, the full destruction of $\mathrm{B}_{10} \mathrm{C}_{2}^{\mathrm{P}}-\mathrm{CC}$ icosahedra leads to structural failure. While under $a$ axis compression, the breakage of one of the $\mathrm{B}-\mathrm{C}^{\mathrm{P}}$ bonds within the icosahedron causes the first stress drop. Then all $\mathrm{B}-\mathrm{C}^{\mathrm{P}}$ bonds within icosahedra are broken, leading to the second sudden stress drop. After that, the icosahedra are gradually destroyed until full destruction, leading to structural failure. The above results imply that the $\mathrm{B}-\mathrm{C}^{\mathrm{P}}$ bond within icosahedra is the weakest bond of the $\mathrm{B}_{10} \mathrm{C}_{2}^{\mathrm{P}}-\mathrm{CC}$ structure. Since diatomic carbon chains are more stable than three-atom chains, the $\mathrm{B}-\mathrm{C}^{\mathrm{P}}$ bond within icosahedra of $\mathrm{B}_{10} \mathrm{C}_{2}^{\mathrm{P}}-\mathrm{CC}$ structure is easier to be broken than that of $B_{11} C^{P}-C B C$ structure. Maybe this is the reason for its lowest strength along $c$ axis compression and its lowest toughness.

\section{Conclusions}

In this work, first-principles methods were used to examine the effects of carbon content on the mechanical properties and anisotropic deformation mechanism of boron carbides. In our work, the $\mathrm{B}_{12}-\mathrm{CBC}(13.33$ at $\% \mathrm{C})$ and $\mathrm{B}_{10} \mathrm{C}_{2}^{\mathrm{P}}-\mathrm{CC}(28.75$ at $\% \mathrm{C})$ structures were studied and then compared to the deformation processes of the $\mathrm{B}_{11} \mathrm{C}^{\mathrm{P}}-\mathrm{CBC}$ structure (20 at \% $\mathrm{C}$ ). The elastic constants, bulk modulus, shear modulus, Young's modulus, passion ratio, Pugh's ductility index, Vickers hardness, and anisotropy indexes were examined. The results show that the mechanical properties of boron carbide change with carbon content. The general trend is that the strength and hardness of boron carbides increases with higher carbon concentrations. But with the increase of carbon content, the toughness of boron carbides decreases. The anisotropy of $\mathrm{B}_{10} \mathrm{C}_{2}^{\mathrm{P}}-\mathrm{CC}$ is the lowest among these structures.

For all structures, continuous changes in volume strain and total energy were observed under hydrostatic compression. However, for uniaxial compression, the structures underwent massive structural changes and final failure. The effects of carbon content on the anisotropic deformation mechanism for boron carbides were further examined by comparing their deformation behaviors under $a$ axis and $c$ axis uniaxial compressions. For the $B_{12}-C B C$ structure with 13.33 at $\% C$, under $c$ axis compression, the structural failure is caused by the destruction of icosahedra without bending of chains; while under $a$ axis compression, the formation of new B-B bonds between chains and icosahedra results in a small stress fluctuation before reaching the maximum stress, causing an unrecoverable deformation. After that, the icosahedra in $\mathrm{B}_{12}-\mathrm{CBC}$ are destroyed in turn until the structure is fully destroyed. The anisotropic deformation mechanism is different from that of $\mathrm{B}_{11} \mathrm{C}^{\mathrm{P}}-\mathrm{CBC}$ structure $(20.0$ at $\% \mathrm{C}$ ) because it has $\mathrm{R} \overline{3} \mathrm{~m}$ symmetry without $\mathrm{C}$ atoms in the icosahedra. For the $\mathrm{B}_{10} \mathrm{C}_{2}^{\mathrm{P}}-\mathrm{CC}$ structure with 28.75 at $\% \mathrm{C}$, the anisotropic deformation mechanism is not obvious. The breakage of $\mathrm{B}-\mathrm{C}^{\mathrm{P}}$ bonds is the main reason for the stress drops in $\mathrm{B}_{10} \mathrm{C}_{2}^{\mathrm{P}}-\mathrm{CC}$, suggesting that the $\mathrm{B}_{10} \mathrm{C}_{2}^{\mathrm{P}}-\mathrm{CC}$ structure began to be destroyed. Finally, the full destruction of $\mathrm{B}_{10} \mathrm{C}_{2}^{\mathrm{P}}$ icosahedra leads to structural failure. With the increase of carbon content, the three-atom chains were replaced by diatomic carbon chains. Since diatomic carbon chains are more stable than three-atom chains, the breakage of the weakest $\mathrm{B}-\mathrm{C}^{\mathrm{P}}$ bond within icosahedra causes the $\mathrm{B}_{10} \mathrm{C}_{2}^{\mathrm{P}}-\mathrm{CC}$ structure to begin to be destroyed. Maybe this is the reason for its lowest strength along $c$ axis compression and lowest toughness.

Real boron carbide powder is likely a mixture of different structural configurations. The deformation mechanism will be far more complex. The present simulations explain the effects of carbon content on the anisotropic deformation mechanism for boron carbide clearly. In-depth understanding in the deformation behaviors is the basis for increasing deformation resistance in boron carbides and for designing and synthetic boron carbide composites with high-strength and high-toughness.

Author Contributions: S.X. and J.L. designed the project; J.L. and Y.W. performed the calculations; J.L., S.X., L.L., J.Z. and Y.W. analyzed the results; J.L. and S.X. wrote the manuscript. 
Funding: This research was funded by the National Natural Science Foundation of China (51521001, 51502220, 11402183, U1230107) and the Fundamental Research Funds for the Central Universities of China (WUT: 2017IA002, WUT:2017II07XZ, WUT:2018-III-071GX).

Conflicts of Interest: The authors declare no conflict of interest.

\section{References}

1. Thévenot, F. Boron carbide-A comprehensive review. J. Eur. Ceram. Soc. 1990, 6, 205-225. [CrossRef]

2. Domnich, V.; Reynaud, S.; Haber, R.A.; Chhowalla, M. Boron carbide: Structure, properties, and stability under stress. J. Am. Ceram. Soc. 2011, 94, 3605-3628. [CrossRef]

3. Chen, M.; McCauley, J.W.; Hemker, K.J. Shock-induced localized amorphization in boron carbide. Science 2003, 299, 1563-1566. [CrossRef] [PubMed]

4. Li, J.; Xu, S.; Liu, L.; Wang, Z.; Zhang, J.; Liu, Q. Mechanism for amorphization of boron carbide under complex stress conditions. Mater. Res. Express 2018, 5, 55204. [CrossRef]

5. Vogler, T.J.; Reinhart, W.D.; Chhabildas, L.C. Dynamic behavior of boron carbide. J. Appl. Phys. 2004, 95, 4173-4183. [CrossRef]

6. Yan, X.Q.; Tang, Z.; Zhang, L.; Guo, J.J.; Jin, C.Q.; Zhang, Y.; Goto, T.; McCauley, J.W.; Chen, M.W. Depressurization amorphization of single-crystal boron carbide. Phys. Rev. Lett. 2009, 102, 075505. [CrossRef] [PubMed]

7. Clark, H.K.; Hoard, J.L. The Crystal Structure of Boron Carbide. J. Am. Chem. Soc. 1943, 65, $2115-2119$. [CrossRef]

8. Lazzari, R.; Vast, N.; Besson, J.M.; Baroni, S.; Corso, A.D. Atomic Structure and Vibrational Properties of Icosahedral $\mathrm{B}_{4} \mathrm{C}$ Boron Carbide. Phys. Rev. Lett. 1999, 83, 3230-3233. [CrossRef]

9. Morosin, B.; Kwei, G.H.; Lawson, A.C.; Aselage, T.L.; Emin, D. Neutron powder diffraction refinement of boron carbides nature of intericosahedral chains. J. Alloys Compd. 1995, 226, 121-125. [CrossRef]

10. Madhav Reddy, K.; Guo, J.J.; Shinoda, Y.; Fujita, T.; Hirata, A.; Singh, J.P.; McCauley, J.W.; Chen, M.W. Enhanced mechanical properties of nanocrystalline boron carbide by nanoporosity and interface phases. Nat. Commun. 2012, 3, 1052-1057. [CrossRef] [PubMed]

11. Ektarawong, A.; Simak, S.I.; Alling, B. Carbon-rich icosahedral boron carbides beyond B4 C and their thermodynamic stabilities at high temperature and pressure from first principles. Phys. Rev. B 2016, 94, 054104. [CrossRef]

12. Jay, A.; Vast, N.; Sjakste, J.; Duparc, O.H. Carbon-rich icosahedral boron carbide designed from first principles. Appl. Phys. Lett. 2014, 105, 031914. [CrossRef]

13. Kwei, G.H.; Morosin, B. Structures of the boron-rich boron carbides from neutron powder diffraction: Implications for the nature of the inter-icosahedral chains. J. Phys. Chem. 1996, 100, 8031-8039. [CrossRef]

14. Saal, J.E.; Shang, S.; Liu, Z.K. The structural evolution of boron carbide via ab initio calculations. Appl. Phys. Lett. 2007, 91, 231915. [CrossRef]

15. Taylor, D.E.; McCauley, J.W.; Wright, T.W. The effects of stoichiometry on the mechanical properties of icosahedral boron carbide under loading. J. Phys. Condens. Matter 2012, 24. [CrossRef] [PubMed]

16. Gosset, D.; Colin, M. Boron carbides of various compositions: An improved method for X-rays characterisation. J. Nucl. Mater. 1991, 183, 161-173. [CrossRef]

17. Jiménez, I.; Sutherland, D.; van Buuren, T.; Carlisle, J.; Terminello, L.; Himpsel, F. Photoemission and x-ray-absorption study of boron carbide and its surface thermal stability. Phys. Rev. B 1998, 57, 13167-13174. [CrossRef]

18. Vast, N.; Lazzari, R.; Besson, J.; Baroni, S.; Dal Corso, A. Atomic structure and vibrational properties of icosahedral $\alpha$-boron and $\mathrm{B}_{4} \mathrm{C}$ boron carbide. Comput. Mater. Sci. 2000, 17, 127-132. [CrossRef]

19. Konovalikhin, S.V.; Ponomarev, V.I. Carbon in boron carbide: The crystal structure of $B_{11.4} C_{3.6}$. Russ. J. Inorg. Chem. 2009, 54, 197-203. [CrossRef]

20. Aselage, T.L.; Tissot, R.G. lattice Constants of Boron Carbides. J. Am. Ceram. Soc. 1992, 75, $2207-2212$. [CrossRef]

21. Cheng, C.; Reddy, K.M.; Hirata, A.; Fujita, T.; Chen, M. Structure and mechanical properties of boron-rich boron carbides. J. Eur. Ceram. Soc. 2017, 37, 4514-4523. [CrossRef] 
22. An, Q.; Goddard, W.; Cheng, T. Atomistic explanation of shear-induced amorphous band formation in boron carbide. Phys. Rev. Lett. 2014, 113, 1-5. [CrossRef] [PubMed]

23. An, Q.; Goddard, W.A. Nanotwins soften boron-rich boron carbide $\left(\mathrm{B}_{13} \mathrm{C}_{2}\right)$. Appl. Phys. Lett. 2017, 110, 111902. [CrossRef]

24. Yang, X.; Goddard, W.A.; An, Q. Structure and Properties of Boron-Very-Rich Boron Carbides: B 12 Icosahedra Linked through Bent CBB Chains. J. Phys. Chem. C 2018, 122, 2448-2453. [CrossRef]

25. Li, J.; Xu, S.; Zhang, J.; Liu, L.; Liu, Q.; She, W.; Fu, Z. Ab initio study on the anisotropy of mechanical behavior and deformation mechanism for boron carbide. Chin. Phys. B 2017, 26, 047101. [CrossRef]

26. Clellan, K.J.M.C.; Chu, F.; Roper, J.M.; Shindo, I. Room temperature single crystal elastic constants of boron carbide. J. Mater. Sci. 2001, 36, 3403-3407. [CrossRef]

27. Korotaev, P.; Pokatashkin, P.; Yanilkin, A. The role of non-hydrostatic stresses in phase transitions in boron carbide. Comput. Mater. Sci. 2016, 121, 106-112. [CrossRef]

28. Liu, D.; Li, S.; Bian, F.; Meng, X. First-principles investigation on the electronic and mechanical properties of Cs-doped $\mathrm{CH}_{3} \mathrm{NH}_{3} \mathrm{PbI}_{3}$. Materials 2018, 11. [CrossRef] [PubMed]

29. Xie, K.; Jia, Q.; Wang, Y.; Zhang, W.; Xu, J. The Electronic Structure and Optical Properties of Anatase $\mathrm{TiO}_{2}$ with Rare Earth Metal Dopants from First-Principles Calculations. Materials 2018, 11, 179. [CrossRef] [PubMed]

30. Zhang, W.; Chai, C.; Song, Y.; Fan, Q.; Yang, Y. Structural, Mechanical, Anisotropic, and Thermal Properties of AlAs in $o$ C12 and $h$ P6 Phases under Pressure. Materials 2018, 11, 740. [CrossRef] [PubMed]

31. Kresse, G.; Furthmüller, J. Efficient iterative schemes for ab initio total-energy calculations using a plane-wave basis set. Phys. Rev. B 1996, 54, 11169-11186. [CrossRef]

32. Kresse, G. From ultrasoft pseudopotentials to the projector augmented-wave method. Phys. Rev. B 1999, 59, 1758-1775. [CrossRef]

33. Kresse, G.; Furthmüller, J. Efficiency of ab-initio total energy calculations for metals and semiconductors using a plane-wave basis set. Comput. Mater. Sci. 1996, 6, 15-50. [CrossRef]

34. Ranganathan, S.I.; Ostoja-Starzewski, M. Universal elastic anisotropy index. Phys. Rev. Lett. 2008, 101, 055504. [CrossRef] [PubMed]

35. Chen, X.Q.; Niu, H.; Li, D.; Li, Y. Modeling hardness of polycrystalline materials and bulk metallic glasses. Intermetallics 2011, 19, 1275-1281. [CrossRef]

36. R. Hill The Elastic Behaviour of a Crystalline Aggregate. Proc. Phys. Soc. Sect. A 1951, 65, 349-354. [CrossRef]

37. Sun, L.; Gao, Y.; Xiao, B.; Li, Y.; Wang, G. Anisotropic elastic and thermal properties of titanium borides by first-principles calculations. J. Alloys Compd. 2013, 579, 457-467. [CrossRef]

38. Aryal, S.; Rulis, P.; Ching, W.Y. Mechanism for amorphization of boron carbide $\mathrm{B}_{4} \mathrm{C}$ under uniaxial compression. Phys. Rev. B 2011, 84, 184112. [CrossRef]

39. Silvi, B.; Savin, A. Classification of Chemical-Bonds Based on Topological Analysis of Electron Localization Functions. Nature 1994, 371, 683-686. [CrossRef]

40. Becke, A.D.; Edgecombe, K.E. A simple measure of electron localization in atomic and molecular systems. J. Chem. Phys. 1990, 92, 5397-5403. [CrossRef]

41. Momma, K.; Izumi, F. VESTA 3 for three-dimensional visualization of crystal, volumetric and morphology data. J. Appl. Crystallogr. 2011, 44, 1272-1276. [CrossRef]

42. Zhang, Y.; Mashimo, T.; Uemura, Y.; Uchino, M.; Kodama, M.; Shibata, K.; Fukuoka, K.; Kikuchi, M.; Kobayashi, T.; Sekine, T. Shock compression behaviors of boron carbide (B ${ }_{4}$ C). J. Appl. Phys. 2006, 100, 12-17. [CrossRef]

43. Shirai, K.; Masago, A.; Katayama-Yoshida, H. High-pressure properties of icosahedron-based solid borons. Phys. Status Solidi Basic Res. 2004, 241, 3161-3167. [CrossRef]

(C) 2018 by the authors. Licensee MDPI, Basel, Switzerland. This article is an open access article distributed under the terms and conditions of the Creative Commons Attribution (CC BY) license (http:/ / creativecommons.org/licenses/by/4.0/). 